\title{
The Spatial Development Potentials of Business Districts in Doha: The Case of the West Bay
}

Article in Open House International · December 2013

CITATION

1

3 authors:

\section{Velina Mirincheva}

University College London

4 PUBLICATIONS 4 CITATIONS

SEE PROFILE

\section{Ashraf M. Salama}

University of Strathclyde

99 PUBLICATIONS 252 CITATIONS

SEE PROFILE
READS

7
Florian Wiedmann

University of Strathclyde

22 PUBLICATIONS 33 CITATIONS

SEE PROFILE 


\title{
THE SPATIAL DEVELOPMENT POTENTIALS OF BUSINESS DISTRICTS IN DOHA: THE CASE OF THE WEST BAY
}

\author{
Velina Mirincheva, Florian Wiedmann and Ashraf M. Salama
}

\begin{abstract}
Recent efforts to formulate strategies that will turn Qatar's capital city into a global hub have given rise to a debate about the morphological and functional composition of one of Doha's most prominent areas - West Bay. At the end of the 20th century West Bay, also known as Diplomatic Quarter, was chosen by public initiatives to become the new Central Business District of Doha. Today, the appeal of West Bay as a business hub is contested by other emerging urban centres - such as the highly integrated Al Sadd area, which has attracted a wide range of advanced producer service sectors. It is therefore the objective of this paper to investigate the spatial configuration of Doha's West Bay, which arguably lays the foundations for the socio-economic interdependencies necessary for its vitality and sustenance. In order to quantify its intrinsic urban complexities, Bill Hillier's space syntax methodology is applied, which elucidates, in various scales, global and local grid conditions, and thus can be used for assessments regarding the distribution of land use patterns and infrastructural networks.
\end{abstract}

Keywords: Central Business District, Doha, West Bay, Space Syntax, Spatial Analysis.

\section{INTRODUCTION}

The West Bay has been envisioned as a Central Business District (CBD), which puts an expectation on its spatial and functional parameters. Gregory ef al define the CBD as the the nucleus of an urban area around its most accessible point, containing an internally differentiated concentration of retail and office establishments' (Gregory et. Al, 2009, p. 75). This is certainly a view also shared by Burgess who defines the CBD of American cities of the $20^{\text {th }}$ century, such as Chicago, as the heart of the city, with 'its department stores, its smart shops, its office buildings, its clubs, its banks, its hotels, its theatres, its museums, and its headquarters of economic, social, civic, and political life' (Burgess as cited in Murphy, 2009, p.4). The CBD is not necessarily a delimited area, but rather a morphologically distinct centrality - marked by a concentration of highrise buildings, heavy vehicular and pedestrian traffic, high land value and taxes, and greatest accessibility from all other parts of the city (Murphy, 2009).

Further, the CBD of the digital era depends on the presence of solid 'social infrastructure' that allows for the exchange of tacit knowledge, through encounter and interactions, whose degree of connectivity is directly related to the success of CBD's as strategic economic centres (Sassen, 2001, p. 122). This new logic of globally competitive, economically viable CBD's with integrated social dimension has come to bear spatially on such developments as La Defense in Paris, whose density, accessibility and provision of socio-economic services for its residents rivals its counterparts in London and Barcelona (Birck, 2008). Other cities, such as Toronto and Miami (Sassen, 2000), Singapore (Wong, 2004), and Beijing (Zhou, 1998) have also undergone similar spatial morphosis tailored at becoming not only 'centres for control and command functions for high-value specialized service, [but also] centres for conspicuous consumption and cultural innovation' through the provision of highly efficient social infrastructure (Wong, 2004, p. 37).

These visions translate to the emerging CBD of Doha and its potentials for structuring a spatial environment that not only anchors a corporate foundation, but also connects 'real space' (Hillier, 2008, p. 218) in a network of opportunities for 'probabilistic encounter and co-presence' (Hillier et al, 1987, p.233) that channels the exchange of knowledge and innovation, and contributes to the sustenance of a social capital. It is conjectured here, that this socio-economic overlap depends, first and foremost, on opportunities provided by the spatial configuration and the existence of a globally identifiable urban centrality, where 


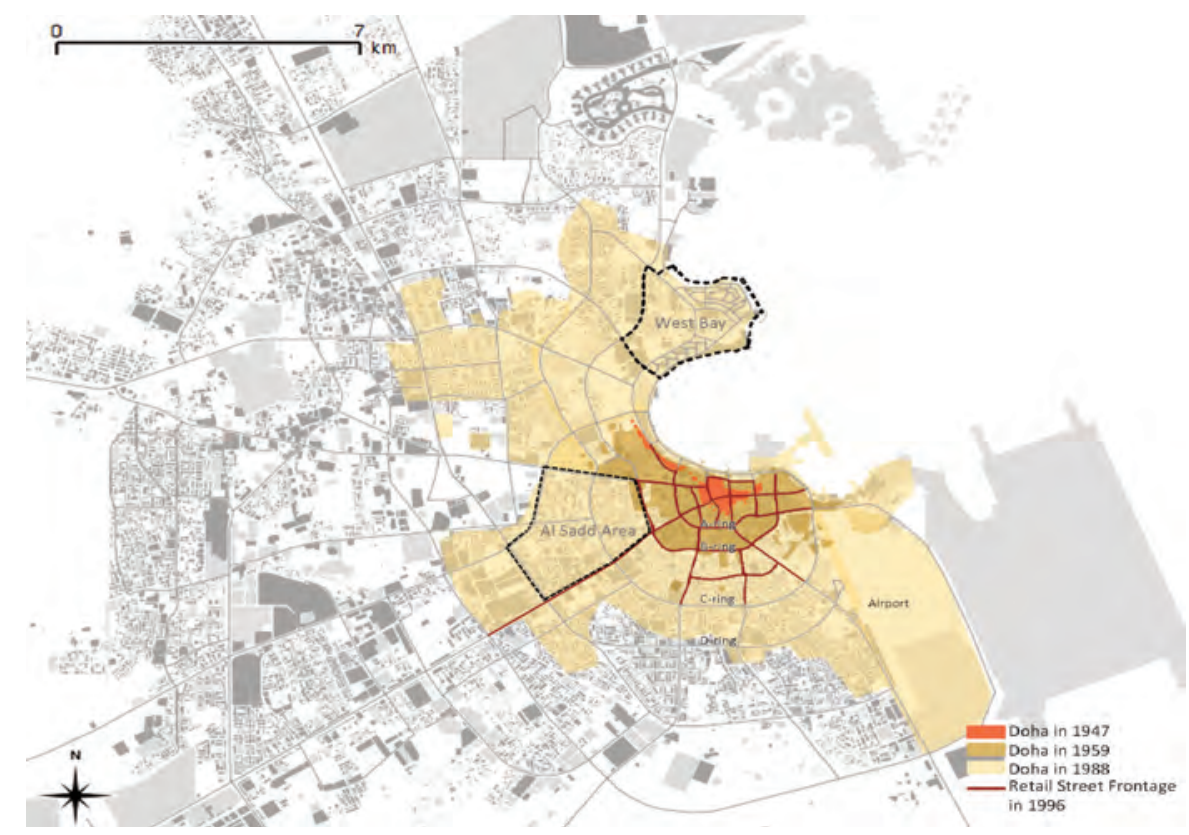

Figure 1. Growth of Doha from 1947 to present, showing formation of ring and radial roads, which host retail activity. (Source: Authors). such, cities acquire a natural tendency to agglomerate economically-laden urban parts in 'live centres... [which are] led by retail, markets, catering and entertainment, and other activities which benefit usually from movement' (Hillier, 1999, p. 107). This process of emerging live centralities will be observed in the CBD of Doha in light of its potential to accommodate not only internally confined corporate and administrative functions, but also to capitalize on the 'urban street buzz' (Hillier, 1996a, p.126), engendered by the provision of socio-economic activity at ground level. various activities take place simultaneously and at various scales. This conjecture is based on the theoretical propositions of space syntax - an evidencebased methodology for analysing the city in terms of 'the patterns of shaped and interlinked spaces intended to facilitate social aims' (Hillier, 2008, p.217).

The urban street network is the largest spatial configuration in a city and it has been argued to have an autonomous power to structure movement flows and patterns of co-presence, in what Hillier et al define as the theory of 'natural move-

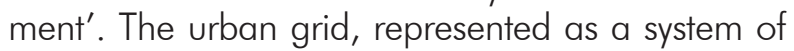
fewest and shortest lines that connect all publically accessed spaces, is seen as the primary generator of movement flows, which are structured in two ways - as a destination or a to-movement or as a choice of route - through-movement (Hillier et al, 1993). The two measures are quantified by the variables of 'integration' (to-movement) and 'choice' (through-movement). Integration and choice, applied at global as well as local radii, reveal the degree of connectivity and accessibility of lines in the urban grid, which is a likely indicator of degree of natural movement, and consequently of advantageous locations for commercial and retail land use.

The agglomeration of socio-economic activity along channels of configurationally-privileged movement flows catalyses a feedback process on the urban grid in what Hillier defines as the 'multiplier effect' of space and movement (Hillier, 1996b, p.43). Consequently, this reciprocal socio-spatial relationship attributes to cities a definition of 'movement economies' (Hillier, 1996b). As

\section{THE EVOLUTION OF THE WEST BAY}

In order to contextualize Doha's Central Business District and to understand the patterns of urbanisation that led to its existence, the following offers a historical overview of the growth and development of the city. It traces the urban expansion from the earliest settlements recorded in aerial photographs and has the objective of providing an insight into an urban past, whose complexities are often underappreciated in modern planning schemes.

The city of Doha is often labelled as an 'Instant City' (Salama, 2008) due to its rapid urbanisation following the discovery of oil in 1939 (Nagy, 2000). This pre-oil period of organically grown localities were soon superseded by the fastpaced city expansion, following the first production of oil ten years after its discovery, in 1947 (Al Buainain, 1999, p.120). The city grew in all directions around the original settlement core (Figure 1) and by the middle of the $20^{\text {th }}$ century infrastructure provisions were emplaced for the construction of the new airport to the south and for connecting to western and northern satellite cities (Al Buainain, 1999). Doha's morphology grew in a radial pattern, forming ring roads that followed the coastal curvature and extending outward with radials that reached towards the rest of the peninsula. These arteries accumulated and channelled movement along their network and subsequently provided the platform for structuring of retail and commercial activities (Figure 1). 
Following a transitional period in the 1960s when the first public policies were drafted and the first ministry founded, the 1970s marked a turning point in government policy and urban development that was conditioned by Qatar's independence from British mandate in 1971 (Wiedmann, 2012). Subsequently, new centralised administration came into being with matters of urban development delegated to the planning section of the Ministry of Municipal Affair and Agriculture (MMAA). Various foreign consultants were invited to advise on planning strategies and devise master plans for future urban development (Al Buainain, 1999).

One of these consultants, William Pereira Associates was commissioned to devise a detailed master plan for what is known as the New District of Doha (NDOD). The NDOD was built on reclaimed land, following recommendations of British consultants Llewellyn-Davies, and composed of extensive housing developments, accommodating, among others, staff for the new Qatar University, hotel and a convention centre, a diplomatic and ministry district, a waterfront promenade (called the Corniche) and a large park surrounding a new business district. The 750-hectare land reclamation, which started in 1974, re-morphed the city bay in a 'crescent shaped shoreline' (Al Buainain, 1999), embedding the new Diplomatic District at the northern tip, thus bestowing upon it a visual dominance, as well as a symbolic specialisation (Figure 1).

During the 1980s only few landmark developments, such as the Sheraton Hotel and the Qatar University, were built in the NDOD development area. The main business centre remained in Al Salata and the A-ring in proximity to the international airport. In the end of the 1990s, the initiated relocation of ministries and semi-public holdings from Dafna to the West Bay led to the first high rise developments. In addition to the perspectives to gain public institutions as tenants, the newly introduced building permits for commercial and residential towers attracted investors to the area. In a period of less than 15 years, more than 88 highrise buildings were built in the West Bay, which became the main icon of modern urbanism in Qatar (Figure 2) (Wiedmann, Salama and Thierstein, 2012). The demand for the shell \& core office space in the West Bay has however, never met initial expectations, with companies looking for smaller, more affordable and fully furnished spaces (100-600sqm), which are mostly located in other emerging business centres along the various ring roads, with C-ring (Al Sadd area) as a primary focus (Asteco Reports, 2011 ; NAl Qatar, 2011). This preference of the private sector has various roots, including spatial accessibility concerns. The following analyses investigate the city's morphological configuration in order to examine the intrinsic spatial parameters of the West Bay in comparison to other business centres in Doha.

\section{THE SPATIAL CONFIGURATION OF THE WEST BAY}

The syntactic analysis of the global condition of Doha during three photographically-recorded periods (1947, 1958 and 1988, as shown in Figure 3), illustrates the logic of the emerging physical profile and would prove insightful justification for the pattern of land use distribution, seen presently. Already within the early, pre-oil historic settlements (Figure $3-a)$, distinct main arteries are detected, around which densely aggregated residential units are structured. With the rapid expansion, following oil discovery and production, the first ring road (A-ring) encircles the historic centre, which still retains remnants of its former main pedestrian roads (Figure 3-

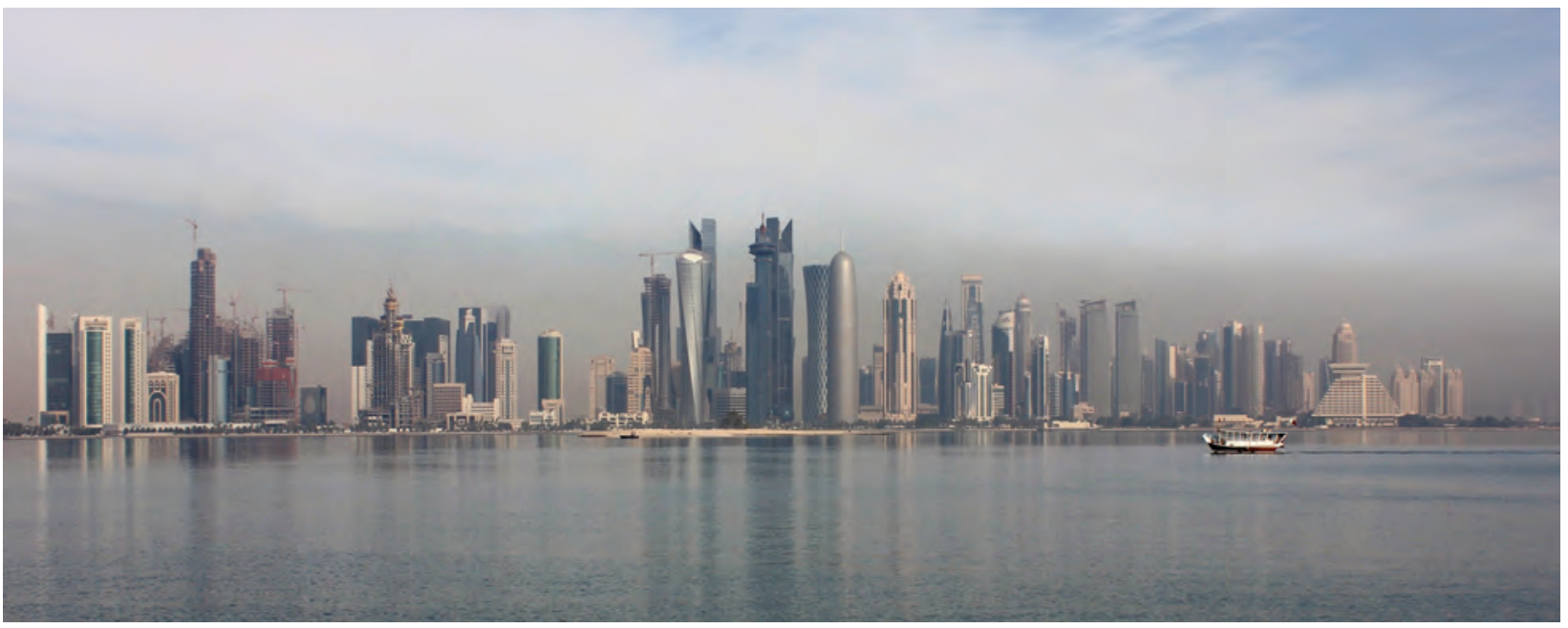

Figure 2. The high-rise waterfront in West Bay. (Source: Authors). 

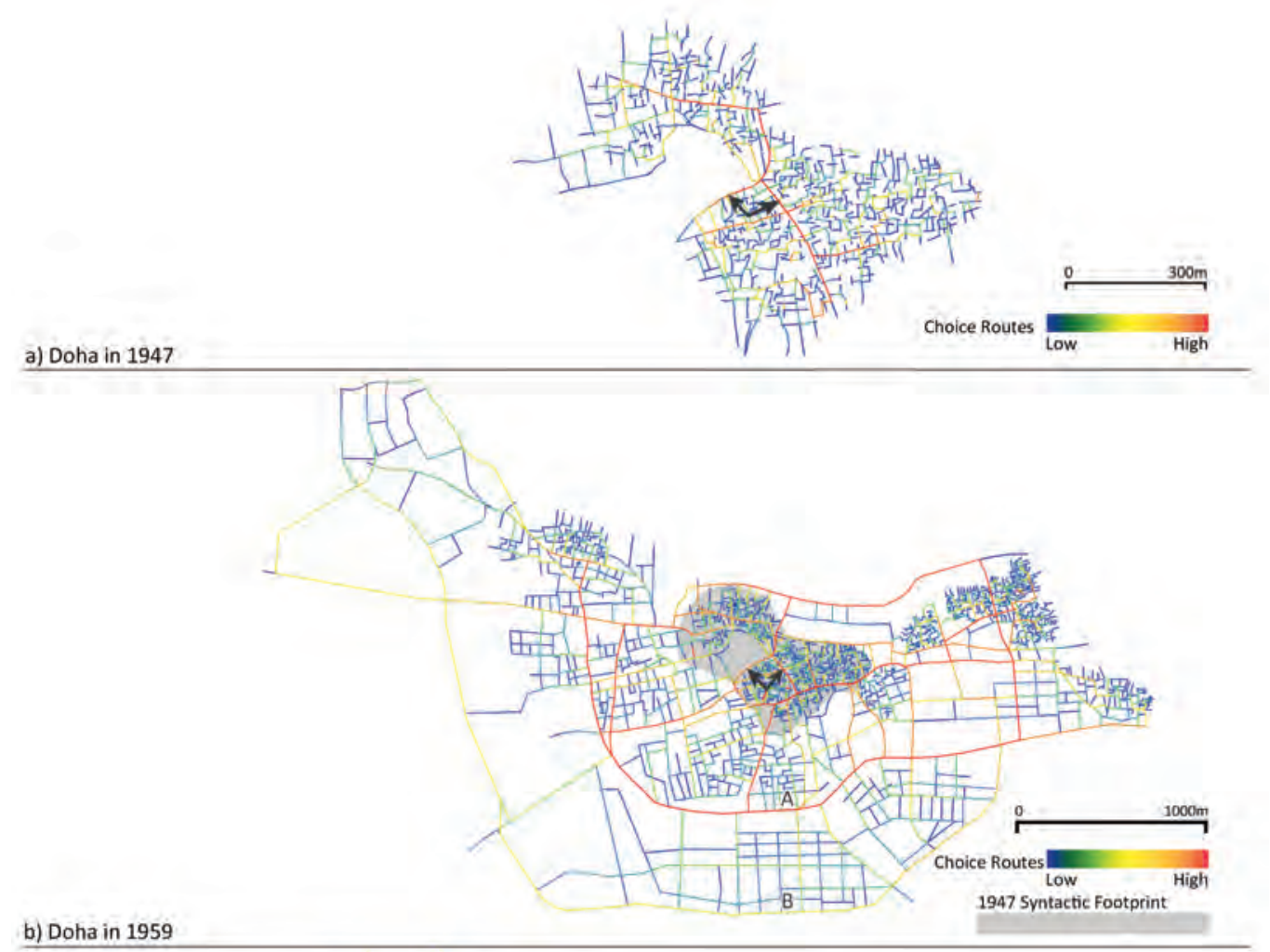

Figure 3. Syntactical analysis of three historical periods (1947, 1959, 1988). (Source: Authors).

b). The A-ring road, in 1959, has become the main spine that channels the most movement along its path, with B-ring road starting to show potential to do the same.

Indeed, by 1988 (Figure 3-c), the ring structure has persistently attained the highest choice values, indicative of the presence of a distinctively strong global 'foreground network of linked centres', that sits within a globally segregated residen- tial background. This strongly differentiated foreground network, which gives the city its universally 'generic' form, is also, according to Hillier, responsible for the channelling of movement and attracting 'movement-seeking' land uses (Hillier, 1996a, p.vi). These, in turn, attract even more movement, creating the 'multiplier effect' that ultimately gives these foreground channels their highest choice, or through-movement, values (Hillier, 1996a, p.vi). 
Thus, here, the morphological profile and global embededness of the ring roads suggest the presence of high degree of commercial activity, while the immediately adjacent short-lined neighbourhoods suggest the predominance of residential quarters.

With specific regards to the West Bay zone, the syntactic map of 1988 (Figure 3-c) locates the CBD within a spatial configuration with lower choice values, signalling a lower potential for this area to naturally structure a movement economy retail which benefits from street movement - along its street network (Hillier, 1996a). This leads to a hypothesis which favours the future capacity of other, more centrally-located centres to engender urban qualities, such as movement-seeking commercial land use, that would attract and sustain a diversified economy and which puts the West Bay in a disadvantage, caused by its spatial configuration.

Figure 4 elucidates the present-day integration, or embededness, of the West Bay within the spatial morphology of Doha. The lack of warm colours within the West Bay zone indicates its relative global segregation, in comparison to the intensity of warm-colour lines found in more centrally located areas, such as within A-ring road. The density of grid lines found in the downtown areas is also indicative of the persistence of historical grid remnants. This density of short and long lines predisposes to the existence of various block sizes and consequently building scales, which welcomes eco-

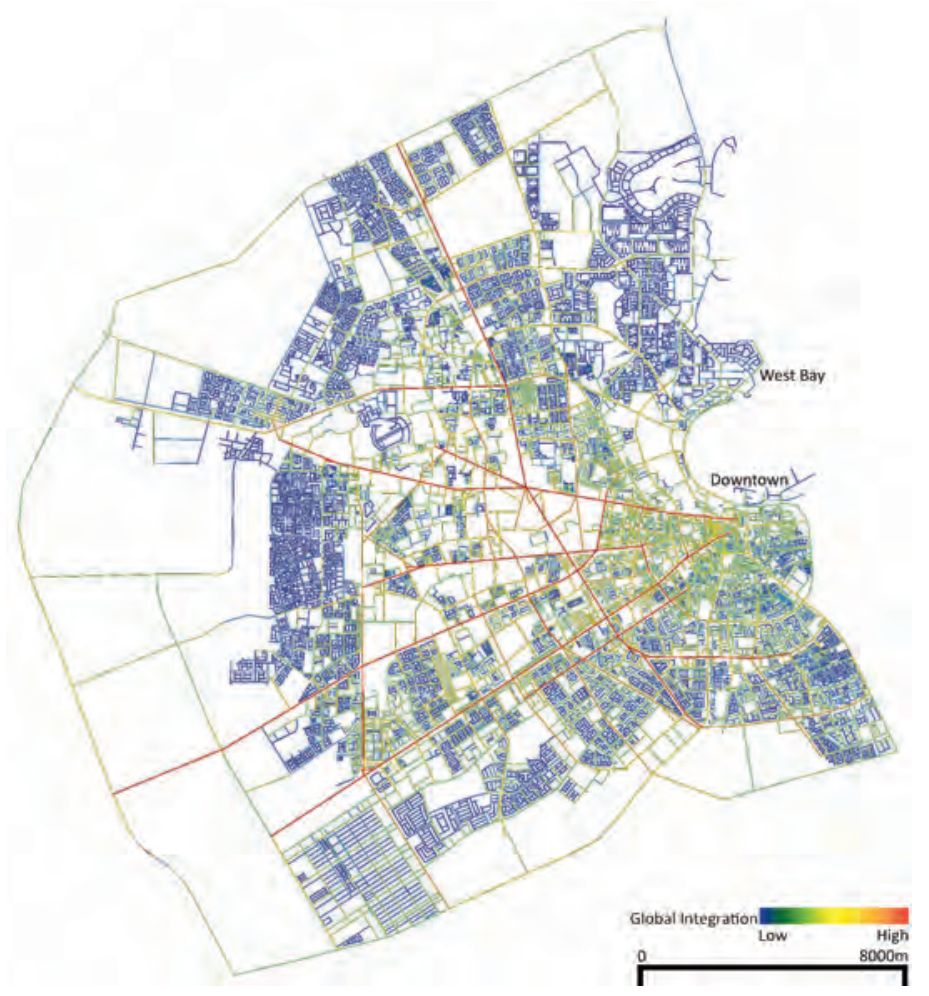

Figure 4. Global syntactic analysis (Integration) of present condition, contextualizing the West Bay to the north. (Source: Authors). nomic and social diversification. Al Sadd area, for instance, is bordered on all sides by high-choice roads, ones that are 'on topologically shortest paths from all lines to all other lines in the system'. The supremacy of the choice network of the Al Sadd area is indicative of the higher densities of varied activities, because of its movement-privileged spatial configuration. This stands in contrast to the Wes Bay areas, whose spatial configuration does not make it an integrated part of the urban fabric of Doha.

The global spatial configuration of Doha reveals there is almost a lack of the usual strongly differentiated centre, from which the city extends in more segregated distant parts. It appears that its morphology is composed of many distinctly segregated parts, which do not come together in a cohesive whole, due to the presence of a strong foreground network that dissects the city into equally segregated urban enclaves. Thus, the city seems to have been 'put together' globally, a result of extensive post-1970s top-down planning, which has almost annihilated the potential for organic growth of spatial complexities.

On a more local scale, when compared to Al Sadd area again, the West Bay's local centralities (its main arteries) seem to lose their potency, while in Al Sadd, they stay persistently strong (Figure 5). This is due to the fact that local centralities in the Al Sadd area are also part of the global to- and through-movement and network (Figure 4), which is not the case in West Bay; it appears as a segregated to-movement destination. Thus, while the highest choice values in Al Sadd slide along the same line, in West Bay they quickly disappear towards the edges, of which only the shoreline movement corridor the Corniche - emerges as the highest choice at the smallest radius (Figure 5).

This difference between choice values in different locations is also indicative of the different spatial morphology of Doha's urban fabric. Again, while in the Al Sadd area the long lines, accounting for primacy in a road hierarchy, are angularly intersected by a lower order network of shorter lines, in the West Bay area long and short lines seem to create not angles, but loops. This is clearly evident in the figure ground models of the two zones as shown in Figure 6. The loopgrid in West Bay, exacerbated by one-way vehicular movement, indeed stands as the counteract of the through-movement angular line-grid network in the Al Sadd area.

Moreover, in terms of building massing, the very centre of the West Bay is currently occupied by a shopping mall complex and the 


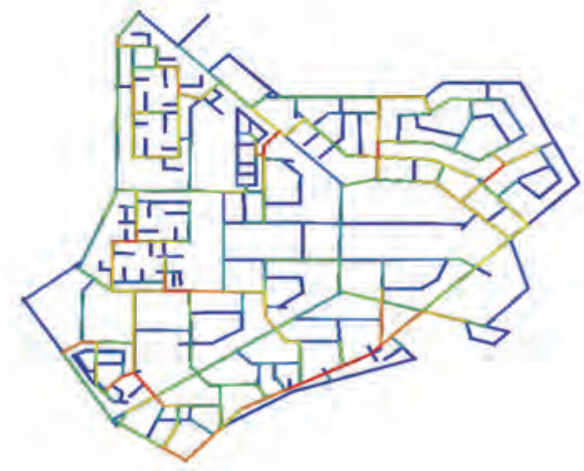

a) West Bay

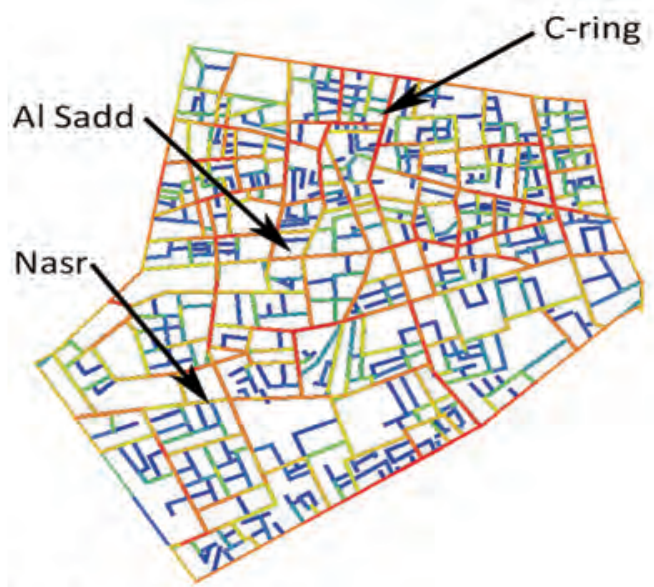

b) Al Sadd

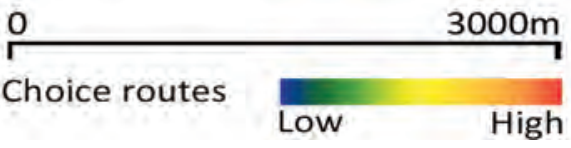

Figure 5. Analysis of local syntax of West Bay and Al Sadd area. (Source: Authors).

building site of an equally large convention centre, encircled by a looping road system (Figure 7-a). This spatial colonization annihilates the possibility of a 'live centrality', characterized by a 'compact and interaccessible layout' (Hillier, 1999, p.121). The lack of it affects opportunities for the natural co-presence of both corporate-laden and sociallyladen activities and leads to a spatial and functional segregation at the very core of the business district.

The longer syntactical lines in the West Bay area (Figures 5 and 7) are also indicative of the size of the bigger urban blocks (Hillier, 1999). Not only is the building density in West Bay drastically lower than that of Al Sadd, but also the locations of buildings within the plots is quite different. Contrary to Al Sadd area, buildings in the West Bay are offset from

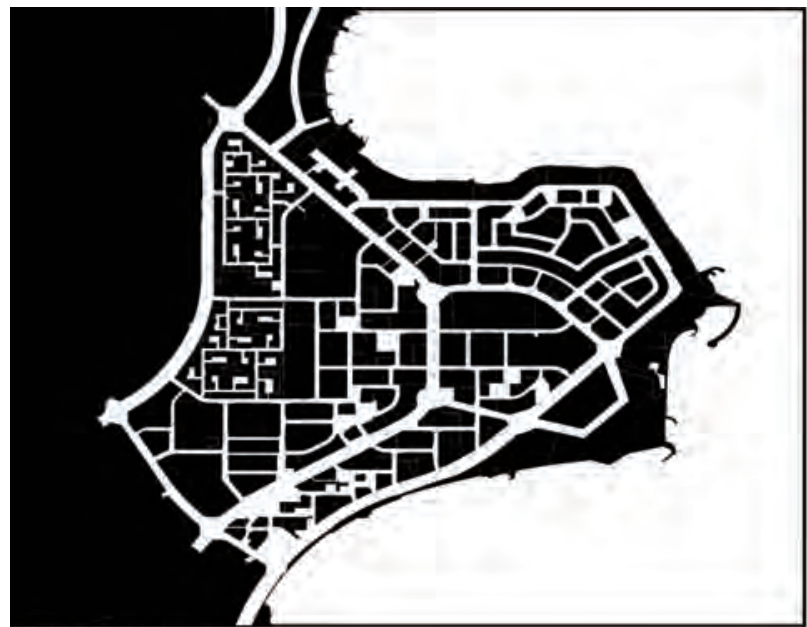

a) West Bay the main through- movement arteries (Figure 8-left) - the ones with highest choice values - and have two main entrances, with the more active one located on the back side, accessed through the secondary road network (Figure 9-left).

As such, the building layout leaves almost no possibility for creating interface between building occupants and street pedestrians. The lack of commercial ground floor activity further limits the possibilities for a social dynamic, not only for West Bay's corporate occupants, but also for visitors to the area.

Moreover, the spatial segregation in the West Bay translates into a distinct functional spatialisation. Most buildings in the West Bay are single-use occupancy, with clusters of retail, service and catering activities located in two shopping

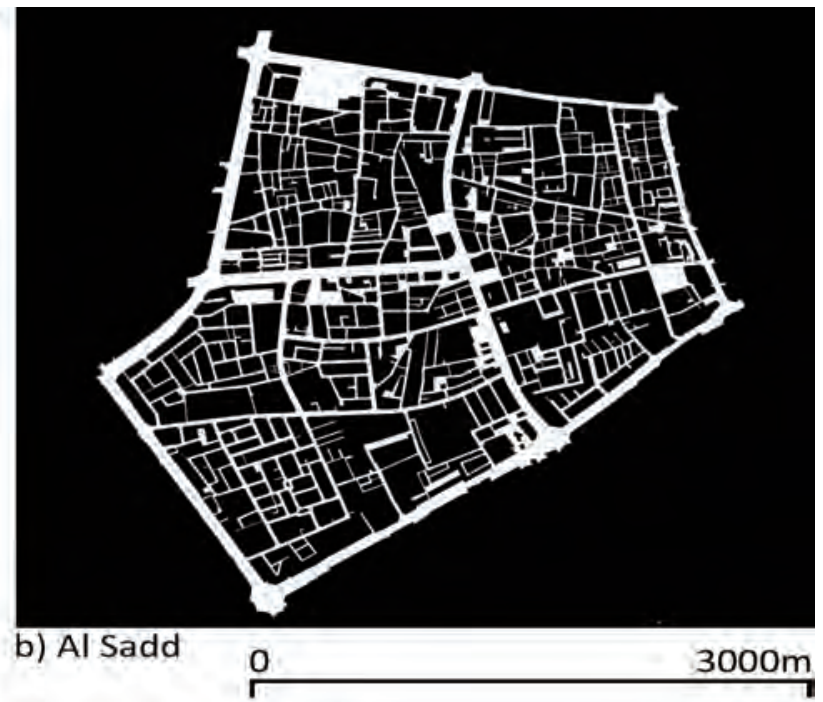

Figure 6. Figure ground model, showing the loop-grid of West Bay (a) and the line-grid of Al Sadd (b). (Source: Authors). 


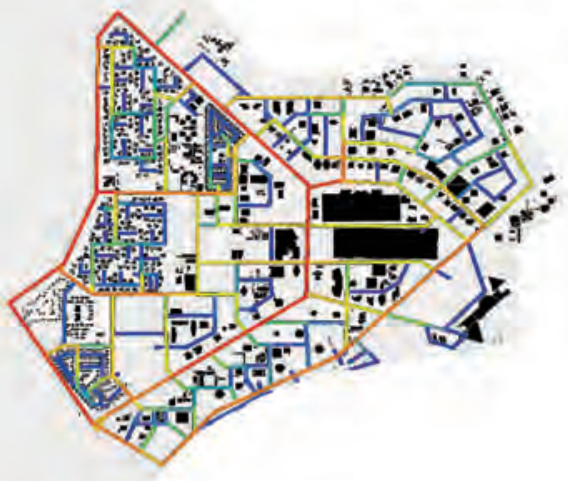

a) West Bay b) Al Sadd

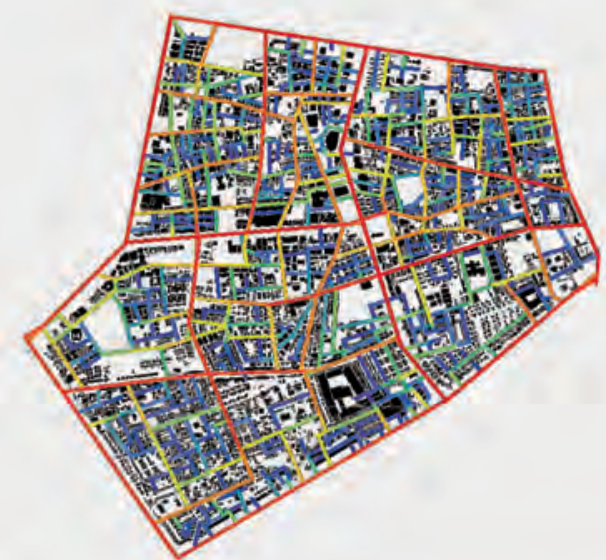

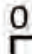

$3000 \mathrm{~m}$

Figure 7. Building density and location within the plots in West Bay (a) and in Al Sadd (b), overlaid with syntactical analysis. (Source: Authors).
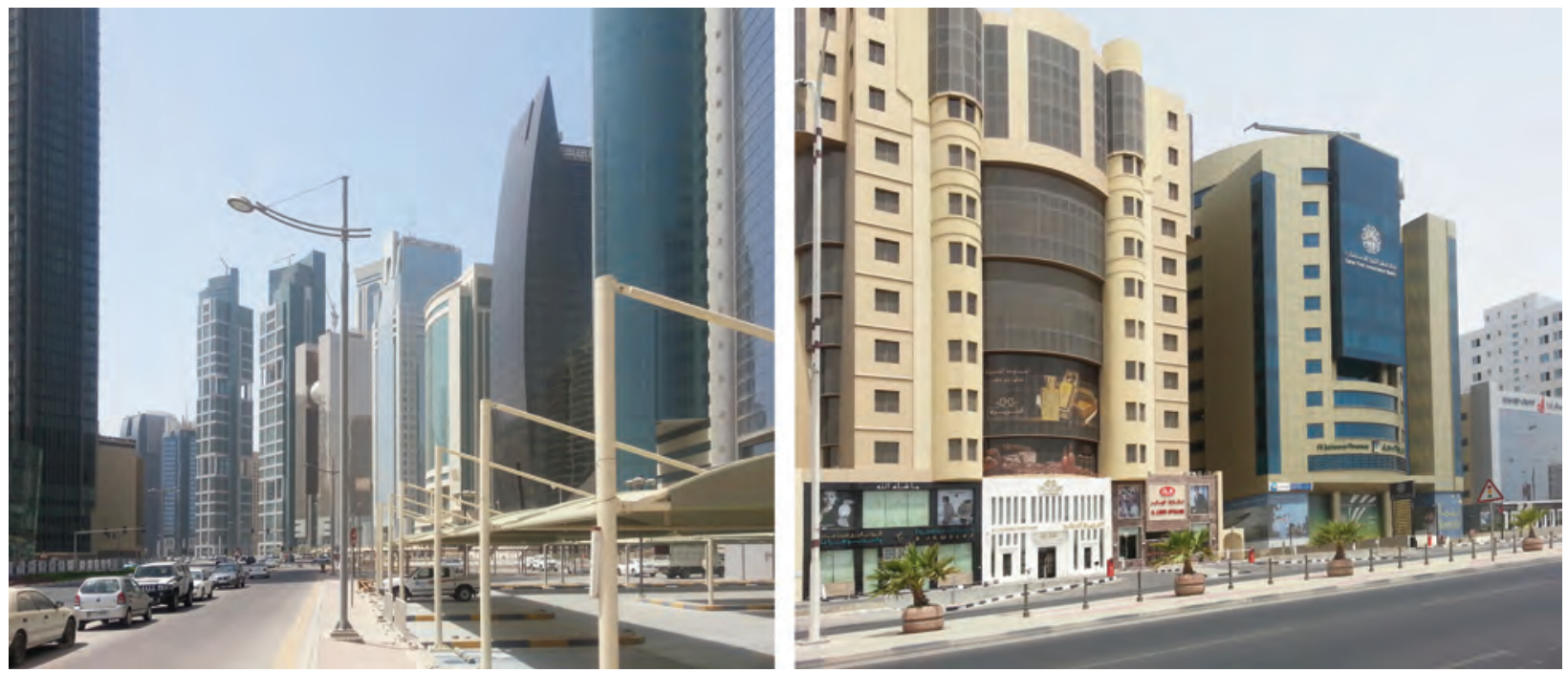

Figure 8. Comparison between street interface conditions in the West Bay (left) and along C-ring road in Al Sadd area (right). (Source: Authors).
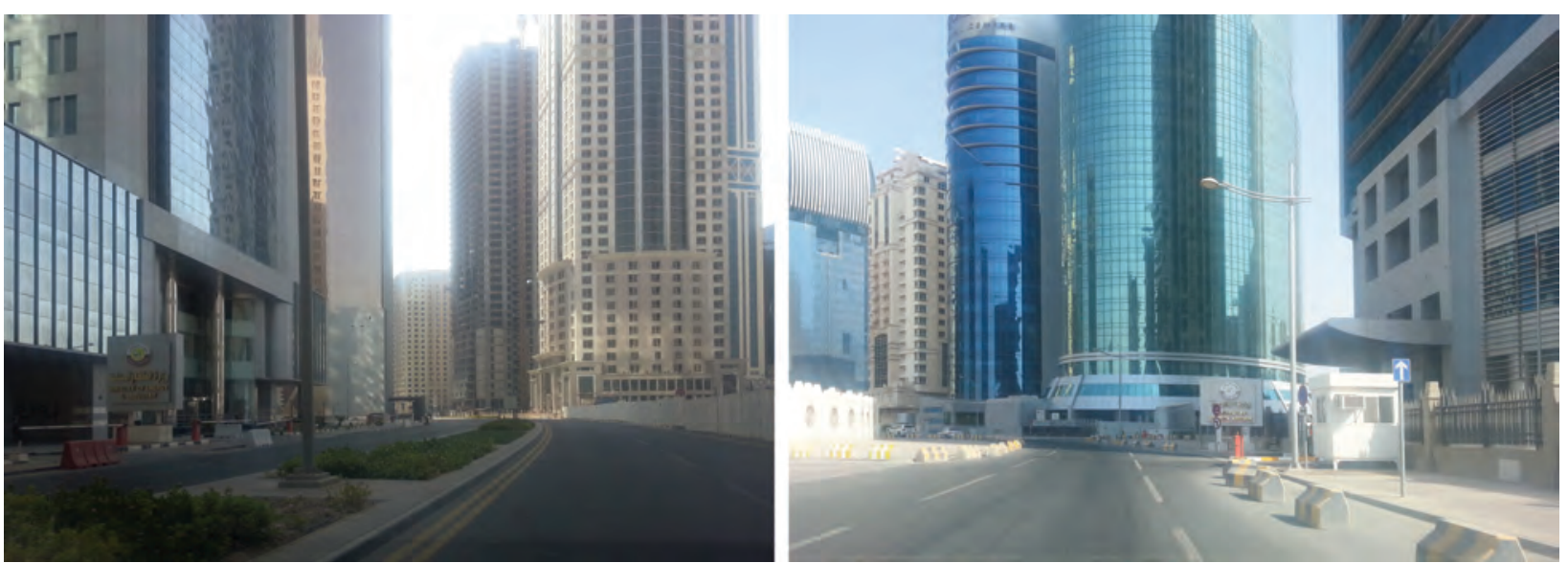

Figure 9. The backside main entrances of buildings in the West Bay. (Source: Authors).

malls. This segregated mega-scaled functional spatialization results in a lack of pedestrian accessibility to density and diversity, burdening Doha's vision of becoming a 'compact...polycentric' city with opportunities for mixed-use 'urban developments that would include elements to service all aspects of 


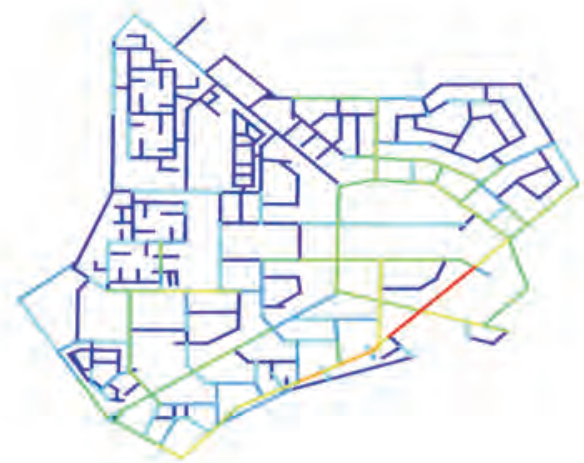

a) Existing configuration of West Bay

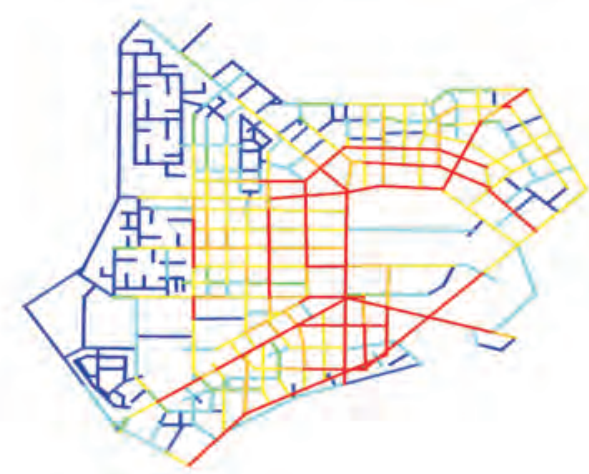

b) Proposed grid intensification of West Bay

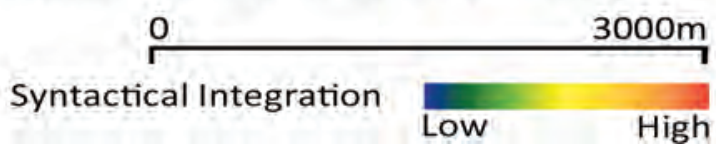

Figure 10. Syntactical integration analysis of the West Bay zone, comparing existing (left) and proposed conditions (right).

(Source: Authors).

one's existence in urban space' (QSC 2011, p.15).

\section{THE POTENTIAL RECONFIGURATION OF SPATIAL STRUCTURES IN WEST BAY}

Based on the previous spatial analyses it could be said, that the West Bay district has amounted various incapacities that impede its affirmation of a vibrant central business district. These are arguably due to a combination of a lack of historical traces in the area, coupled with an over-simplified topdown planning, resulting in a spatial and functional segregation, which ignores the pedestrian scale at street level. It could be further said, there has been a lack of research into the spatial potentials of both historical city centres and central business districts, such as global and local grid conditions, density and diversity of uses, as well as varied building scales. The spatial accumulation of these is retained essential for allowing the overlap of corporate and social infrastructure towards establishing a dynamic business urban core.

In order to remedy this spatial deficiency, one recommendation would be a Siksna process of grid intensification. The Siksna process advocates optimum block sizes and circulation meshes for CBDs, based on considerations for vehicular and pedestrian movement (Siksna, 1997). In doing so, it also reshapes the block typology into more compact sizes of 3,600-20,000sqm. Such process of grid intensification could reinforce the highest choice routes of the West Bay by providing a better accessibility and interconnectivity. It could also break the loop grid pattern, thus improving on the area's intelligibility. The spatial advantages of an intensified grid could engender potentials for movement economies that would increase the spatial capital - a combination of density and diversity and the accessibility to it, which is arguably the underpinning factor for socio-economic viability.

Figure 10 shows a syntactical intervention of a Siksna process, where the grid of the West Bay is knitted together and intensified. The proposal is successful in defining a discernible core and improving on the integration of axials and radials that knit the spatial network in a continuous more intelligible circulation pattern. Further, the global embededness of the proposed West Bay scheme is examined in Figure 11, where it becomes evident the emergence of a discernible urban core at a global scale. The city's syntactical structure becomes polycentric and the West bay attains a specific grid configuration, which could begin to act as an attractor for movement and diversified land use.

The resulting more permeable grid needs to also host a greater density and diversity of uses at ground level. Such interventions should include the provision of tall landscaping for shading, food and beverage catering along continuous pedestrian sidewalks, as well as increased number of crossings of major boulevards so as to create greater opportunity for interface between corporate occupants and visitors from different parts of the West Bay area. 


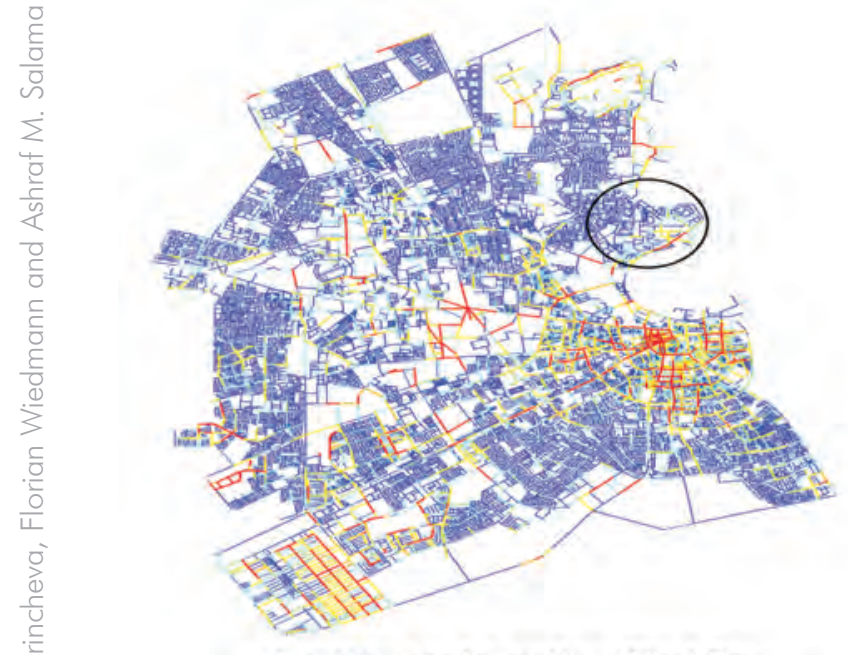

Existing configuration West Bay

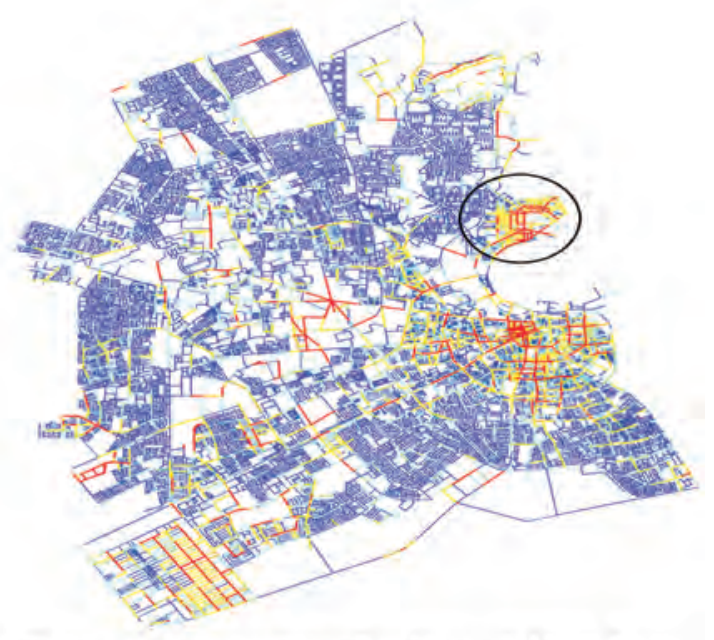

Proposed grid intensification of West Bay

Figure 77. Syntactical analysis of West Bay's integration on a global scale before (left) and after the proposed grid intensification process (right). (Source: Authors).
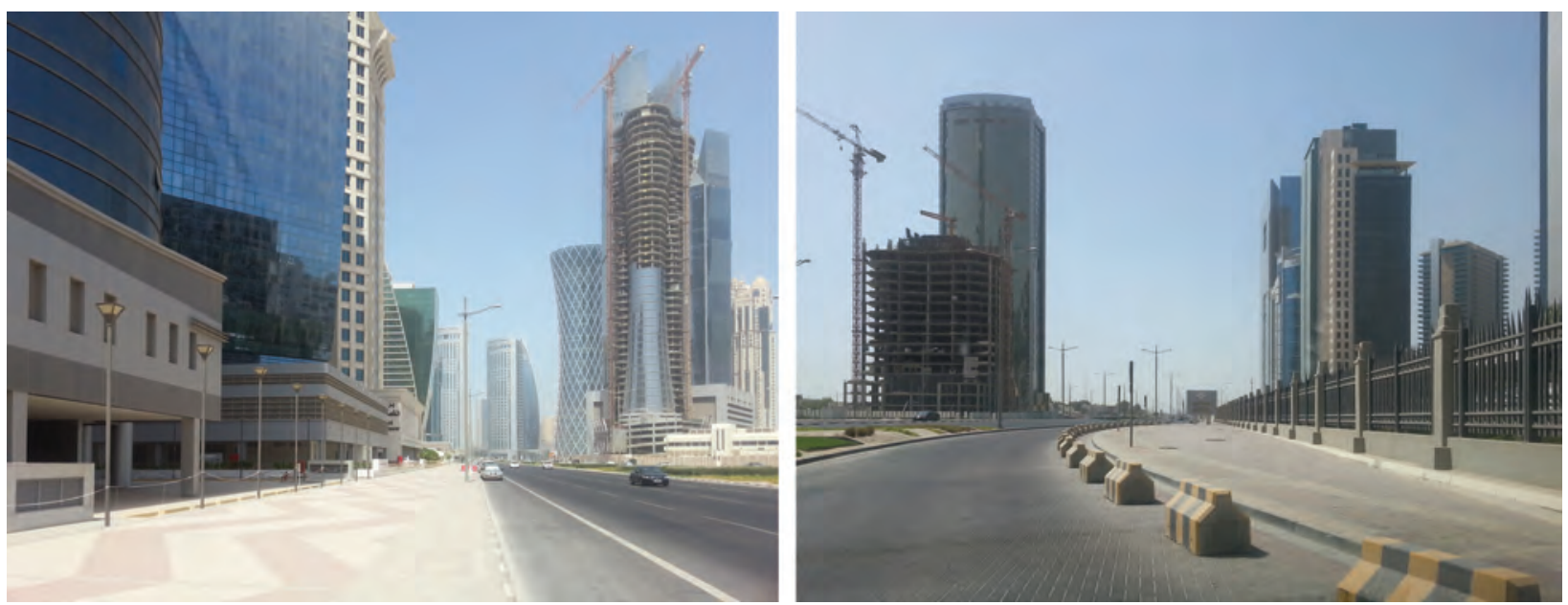

Figure 12. Current street conditions in the West Bay area, which need to be remedied through infill interventions. (Source: Authors).

\section{CONCLUSION}

The recommendations for the improvement of the West Bay area aim to address the challenge of creating a globally distinct spatial centrality and a socio-economic viability that would foster an emerging business and economic diversification. The current spatial deficiencies in the West Bay creating opportunities for the sustenance of movement economies that would constitute an integrated street dynamic. Further recommendations address the current lack of interface conditions between buildings and streets. Increased density, coupled with a diversity of ground floor uses are proposed as the essential changes in the area's spatial capital that would address the needs of the present economy for exchange and interaction between conceptually distant participants that occupy the same urban space.

The recommendations for the improvement of the spatial morphology of the West Bay are based on current conditions and available data and do not take into account specifics of new master plans for the area. Thus, the authors' proposal should be reviewed for its conceptual contribution to the on-going discussion of how to work and structure the physical space in order to address not only functional needs, but also social concerns. More importantly, it is a response particularly to the needs of a growing economy, which seeks those generative urban mechanisms that increase faceto-face contact, social interaction, and breeding grounds for creativity and innovation. Thus, more than a dimensioned design solution, it is a proposition for structuring a spatial overlap of corporate and socio-economic urban activity that would give the West Bay its distinct centrality and spatial capital towards its affirmation as the core Central Business District in Doha.

Given the evolving nature of the West Bay 
and the visions put forward for its development, further studies need to address the realization of some of the future objectives for the area, such as a strong pedestrian axis to community facilities, active frontages on the outskirts and collector roads leading to the waterfront as well as a variety of public spaces including urban plazas in order to secure pedestrian priority, safety, and comfort. Thus, a much deeper understanding of the spatial needs of a diversified economy needs to be emplaced in future studies for the area, coupled with an appreciation of those local cultural variants that shape the area's spatial complexities and sustain its evolution.

\section{ACKNOWLEDGEMENT}

This study is developed as part of a comprehensive funded research project of the National Priorities Research Program, QNRF-Qatar National Research Fund (NPRP 09 - 1083 - 6 - 023).

\section{REFERENCES}

QATAR CONSTRUCTION SITES. 2011. A vibrant vision for Qatar and Doha, Issue 48, June 2011.

AL BUAINAIN, F. 1999. Urbanisation in Qatar: A Study of the Residential and Commercial Land Development in Doha City, 1970 -1997, PhD Thesis, University of Salford, Salford.

ASTECO. 2011 . Qatar Report 2011. Fourth Quarter, Doha.

BIRCK, D. 2008. La Defense: 50 ans d'histoire. Retrieved 31 July, 2012 from http://www.rfi.fr/francefr/articles/105/article_72229.asp

GREGORY, D., JOHNSTON, R., PRATT, G., WATTS, M. and WHATMORE, S. (eds.) 2009. The Dictionary of Human Geography, Blackwell Publishing Ltd, West Sussex.

HILLIER, B. 1996a. Space is the Machine: a Configurational Theory of Architecture, Cambridge University Press, Cambridge.

HILLIER, B. 1996b. Cities as Movement Economies, in Urban Design International, 1(1), 41-60.

HILLIER, B. 1999. Centrality as a Process: Accounting for Attraction Inequalities in Deformed Grids, in Urban Design International, 4(3-4), 107-127.

HILLIER, B. 2008. Space and Spatiality: What the Built Environment needs from Social Theory, in Building Research and Information, 36(3), 216-230.

HILLIER, B., BURDETT, R., PEPONIS, J. and PENN, A. 1987. Creating Life: Or, does Architecture determine Anything? in Architecture and Comportement / Architecture and Behaviour, 3(3), 233-250.

HILLIER, B., PENN, A., HANSON, J., GRAJEWSKI, T. and XU, J. 1993. Natural Movement: Or, Configuration and Attraction in Urban Pedestrian Movement, in Environment and Planning B: Planning and Design, 20, 29-66.

MURPHY, R. 2009. The Central Business District: a Study in Urban Geography, Aldine-Atherton, Chicago, IL.

NAGY, S. 2000. Dressing Up Downtown: Urban Development and Government Public Image in Qatar, in City \& Society, 12, 125-147.

NAI QATAR 2011 . Real Estate Market Report, Doha.

SALAMA, A. M. 2008. Doha: Between Making an Instant City and Skirmishing Globalization, in Architecture and Urbanism in the Middle East, Special Edition of Viewpoints, Middle East Institute, American University, Washington, DC. 40-44. 
SASSEN, S. 2000. Cities in a World Economy, 2nd Ed, Pine Forge Press, Thousand Oaks, CA.

SASSEN, S. 2001. The Global City, Princeton University Press, Princeton, NJ

SIKSNA, A. 1997. The Effects of Block Size and Form in North American and Australian City Centres, in Urban Morphology, 1, 19-33.

WIEDMANN, F. 2012, Post-oil Urbanism in the Gulf: New Evolution in Urban Governance and the Impact on Urban Morphologies, SVH Verlag, Stuttgart.

WIEDMANN, F., SALAMA, A. M. and THIERSTEIN, A. 2012. Urban Evolution of the City of Doha: The Impact of Economic Transformations on Urban Structures, in METU-JFA, Journal of the Faculty of Architecture, Middle East Technical University, Volume 29(2), 35-61.

WONG, T. 2004. The Changing role of the Central Business District in the Digital Era: The Future of Singapore's New Financial District, in Land Use Policy, 21, 33-44.

ZHOU, Y. 1998. Beiijing and the Development of Dual Central Business Districts, in Geographical Review, 88(3), 429-436.

\section{Author(s):}

\section{Velina Mirincheva}

Research Associate

Department of Architecture and Urban Planning

Qatar University Email: mirivel@gmail.com

\section{Dr. Florian Wiedmann}

Post-Doctoral Research Fellow

Department of Architecture and Urban Planning

Qatar University Email: wiedmann.f@gmail.com

\section{Prof. Ashraf M. Salama}

Professor of Architecture and Urbanism Head, Department of Architecture and Urban Planning

Qatar University Email: asalama@qu.edu 